\title{
A REPRESENTAÇÃO DA SEXUALIDADE DA MULHER COM DEFICIÊNCIA FÍSICA NA MÍDIA: O CASO VIVER A VIDA
}


A REPRESENTAÇÃO DA SEXUALIDADE DA MULHER COM DEFICIÊNCIA FÍSICA NA MÍDIA: O CASO VIVER A VIDA ${ }^{1}$

Resumo: Em 2009 no Brasil, foi ao ar pela Rede Globo a telenovela Viver a Vida, que apresentou como protagonista uma mulher com tetraplegia. Nessa telenovela, muitos temas relevantes à vida cotidiana da pessoa com deficiência foram mostrados, incluindo a sexualidade. Nesse artigo, reflito sobre a representação da sexualidade da mulher com deficiência física em Viver a Vida. Acredito que essa questão mereça atenção, uma vez que a sociedade trata a pessoa com deficiência como alguém incapaz e assexuada.

Palavras chave: Gênero; Sexualidade; Telenovela; Mídia; Representação; Deficiência

\section{LA REPRESENTACIÓN DE LA SEXUALIDAD DE LAS MUJERES CON} DISCAPACIDAD FÍSICA EN LOS MEDIOS: EL CASO "VIVER A VIDA" Resumen: En el año 2009 en Brasil, fue presentado por Globo la telenovela Viver a Vida, que presento como protagonista una mujer con tetraplejia. En la telenovela muchos temas que son relevantes para la vida diaria de la persona con discapacidad se ha mostrado, incluida la sexualidad. En este artículo, reflexiono sobre la representación de la sexualidad de las mujeres con discapacidad física en Viver a Vida. Creo que este tema merece atención, ya que la sociedad trata a la persona con discapacidad como alguien incapaz y asexual.

Palabras clave: Género; Sexualidad; Telenovela; Medios; Representación; Discapacidad

THE REPRESENTATION OF THE SEXUALITY OF WOMAN WITH PHYSICAL DISABILITY IN THE MEDIA: THE CASE "VIVER A VIDA" Abstract: In 2009 in Brazil, was presented by Rede Globo, the soap opera Viver a Vida, which presented as a protagonist a woman with tetraplegia. In this soap opera, several themes relevant to the everyday life of disabled people were shown, including the sexuality. In this paper we reflect about the representation of sexuality of the woman with physical disabilities in Viver a Vida. We believe this issue deserves further study, since much of society treats the disabled person as someone incapable, devoid of sexuality.

Keywords: Gender, Sexuality, Soap opera, Media, Representation, Disability

1 Trabalho apresentado no formato pôster no Seventh International Gender and Language Association Conference (Igala 7) - Resignifying Gender and Sexuality in Language and Discourse, 2012. 


\section{INTRODUÇÃO}

Entendo, como Kellner (2001), que a cultura da mídia é a cultura dominante na contemporaneidade. É ela que nos diz como ser homem ou mulher, como trabalhar, como nos vestir, como nos portar. É ela também que constrói nosso "senso de classe, de etnia e raça, de nacionalidade, de sexualidade" (KELLNER,2001: p.09).

A telenovela brasileira é vista como um espaço de intervenção que oferece um campo para a introdução de valores na sociedade. Em 2009, a Rede Globo de Televisão apresentou a telenovela Viver a Vida, em horário nobre (21h), dando visibilidade às pessoas com deficiência ${ }^{2}$ através da personagem tetraplégica Luciana. As representações de pessoas com deficiência, como na telenovela Viver a Vida, podem ajudar a legitimar a existência dos 25 milhões de pessoas com deficiência no Brasil (IBGE), que puderam se reconhecer e reconhecer o seu cotidiano no horário nobre da televisão brasileira. A personagem Luciana, de Viver a Vida, pode ser vista como um marco na discussão sobre a inclusão das pessoas com deficiência na sociedade.

Em minha dissertação de mestrado³, apresento e analiso a representação da pessoa com deficiência na telenovela Viver a Vida, dividindo a análise em seis categorias: A deficiência, Tratamentos de reabilitação, Acessibilidade, Formas de enfrentamento da deficiência, Sexualidade e A visão do outro. No presente texto, apresento primeiramente a metodologia utilizada para tal análise. Em momento posterior, discuto a importância das representações como formas de criar significados. Após, apresento o conceito de normalização e como vejo a deficiência, a partir dos Disability Studies. Por fim, apresento a análise realizada sobre a representação da sexualidade da mulher com deficiência na telenovela Viver a Vida.

\section{METODOLOGIA}

Realizei a análise da representação da pessoa com deficiência na telenovela

2 Na Convenção Internacional para Proteção e Promoção dos Direitos e Dignidade das Pessoas com Deficiência, ficou decidido que o termo correto utilizado para falar sobre pessoas com deficiência seria "pessoas com deficiência” e não portador de deficiência ou deficiente.

3 Entre a vitimização e a divinização: a pessoa com deficiência em Viver a Vida (SILVEIRA, 2012). 
Viver a Vida a partir da abordagem chamada por Kellner (2001) de multiperspectívica, na qual as fronteiras entre disciplinas são ultrapassadas na ida do texto ao contexto. Para o autor, a inclusão da análise do contexto em que o texto midiático é produzido é fundamental. Dessa forma, além de olhar para o texto da telenovela, lanço um olhar também sobre as demais representações sobre as pessoas com deficiência postas em circulação durante a telenovela Viver $a$ Vida.

Assim, por entender que o discurso da telenovela está relacionado com a sociedade em que está inserido, selecionei reportagens sobre a pessoa com deficiência física que foram veiculadas durante o período de exibição da telenovela (de 01/09/2009 à 01/06/2010), nas revistas Veja e Época, nos jornais Zero Hora e Folha de São Paulo e nos meios voltados para o segmento de pessoas com deficiência, revista Sentidos e jornal Na Luta. Realizei tal tarefa tendo em vista o processo sócio-histórico de construção do que é a deficiência, tratando a deficiência associada com a ideia de normalidade, sua historicidade e sua inclusão no meio social.

\section{REPRESENTAÇÕES, NORMALIZAÇÃO E SIGNIFICADOS}

Para pensar a representação das pessoas com deficiência na telenovela, utilizo a definição de Hall, quando diz que a representação é

o processo através do qual os membros de uma cultura fazem uso da linguagem (geralmente definida como qualquer sistema que dispõe de signos, qualquer sistema de significação) para produzir sentido. Esta definição, por sua vez, carrega a importante premissa que as coisas - objetos, pessoas e eventos do mundo - não têm neles nenhum significado final ou verdadeiro. Somos nós, na sociedade - dentro de culturas humanas - quem fazemos as coisas ter sentido, significar (Hall, 1997, p. 61).

É através do uso da linguagem que damos sentido às coisas que nos cercam. $\mathrm{E}$, considerando que os significados são constantemente produzidos e reproduzidos, eles podem também ser modificados. Assim, a sociedade que hoje ainda dá um valor negativo à pessoa com deficiência, pode mudar essa ideia, através de novas representações, que criem novos significados sobre as deficiências.

Neste estudo, utilizo os conceitos de Kellner para a análise da cultura midiática. Segundo o autor, 
numa cultura contemporânea dominada pela mídia, os meios dominantes de informação e entretenimento são uma fonte profunda e muitas vezes não percebidas de pedagogia cultural: contribuem para nos ensinar como nos comportar e o que pensar e sentir, em que acreditar, o que temer e desejar - e o que não (KELLNER, 2001, p. 10).

Dessa forma, entendo que a cultura da mídia pode contribuir para a reprodução de discursos estereotipados e preconceituosos quando falamos em grupos minoritários (sexo, idade, classe, cor, habilidades), bem como pode propiciar uma visão mais positiva sobre esses grupos.

A visibilidade midiática pode ser entendida como espaço de negociação de sentidos da sociedade e as instituições midiáticas ligam os indivíduos desta sociedade lançando temas a serem discutidos, que poderão produzir sentidos, sentimentos e mudanças sociais. Para Lopes (1999), a tele-ficção no Brasil ocupa um espaço de reflexão e problematização da nação, além de agendar os assuntos da vida cotidiana. Para Hamburger (2005, p. 27), no Brasil, a telenovela é "palco privilegiado da problematização da nacionalidade".

As representações das pessoas com deficiência física na mídia é tema que já despertou o interesse de pesquisadores americanos e ingleses, que, por sua vez, criaram os Disability Studies, que se propõem a desconstruir o aparato de poder e de saber que gira em torno daquilo que naturalizamos como o outro deficiente (Skliar, 2003). Os Disability Studies formam um campo emergente de pesquisa que une as ciências sociais, as humanidades e as ciências médicas, incluindo a "comunidade com deficiência" a participar dessas pesquisas para responder às mais diversas questões referentes às deficiências e relações das pessoas com deficiência e o meio em que vivem (ALBRECHT, SEELMAN \& BURY, 2001). Esses estudos examinam como os efeitos da história cultural, forças estruturais, instituições, formas de acesso a bens e oportunidades afetam as pessoas com deficiência e que pretendem entender e contribuir para o entendimento do mundo e oferecer perspectivas de melhoramento da vida das pessoas com deficiência.

Em estudo sobre a representação das pessoas com deficiência na mídia, Barnes (1992) identifica os estereótipos culturais mais frequentemente mostrados pela mídia sobre as pessoas com deficiência: lamentável, patético, objeto de violência, sinistro, do mal, "curioso", aleijado, objeto do ridículo, como seu próprio mal ou próprio inimigo, sexualmente anormal, incapaz de participar da vida em comunidade e como indivíduo normal. 
Segundo Lennard Davis (apud. Skliar, 2003) a alteridade deficiente foi, por muito tempo isolada, oprimida, encarcerada e observada. Escreveu-se sobre ela, instruíram-na, regularam, institucionalizaram, reprimiram e controlaram até tal ponto que a experiência resultante pode ser comparada a de outros grupos minoritários.

O preconceito com a pessoa com deficiência pode ser explicado por um histórico de normalização em nossa sociedade. Skliar (2003) ao explicar o surgimento da normalização, remonta aos pensamentos de Foucault, quando este diz que o

processo de alterização da deficiência foi construído e inventado com a industrialização e com um conjunto de práticas e discursos indissoluvelmente vinculados a noções tais como nacionalidade, raça, gênero, criminalidade, orientação sexual etc. do final do século XVIII e início de século XIX (FOUCAULT apud SKLIAR, 2003, p. 170).

Essa normalização resultou na institucionalização de paradigmas segregacionistas das pessoas com deficiência. A sociedade parece se conceber enquanto grupo homogêneo, constituído de pessoas normais, cujo conceito de normalidade se faz a partir de padrões estéticos e produtivos que desconsideram a existência singular dos seres. As pessoas com deficiência, por não se enquadrarem nesses padrões, acabam tendo um lugar de diferenciação social (DE CARLI, 2003).

Nesse cenário, Skliar nos esclarece que

as representações que procedem da literatura - e dos filmes e dos jornais e dos documentários etc., cada um com sua óbvia particularidade - têm a capacidade de apresentar a alteridade deficiente em termos de um olhar pendular. Olhar pendular que, sistematicamente, oscila entre a periculosidade, o primitivismo, a obscuridade e a ignorância, ou então seus opostos, isto é, o heroísmo, o emblema da calma, a superação, a civilidade (SKLIAR, 2003, p.189).

Esse olhar pendular faz com que boa parte da sociedade trate a pessoa com deficiência como alguém incapaz, desprovida de vontade, gosto, inteligência e sexualidade, e que precisa de auxílio em todos os campos da vida, digna de pena e merecedora de ajuda.

Desta forma, estudar as representações das pessoas com deficiência a partir dos conceitos de normalização é um processo que deve incluir ações dos mais diversos setores da sociedade, como política, legislação, educação e, tam- 
bém, a mídia e os meios de comunicação.

Dentre os estudos mais representativos nos Disability Studies, estão aqueles que cruzam o estudo de gênero com o estudo da pessoa com deficiência. Nesses estudos, foi identificado que o homem com deficiência é visto como impotente e incapaz de amar e manter relações sexuais. Em contraste, a mulher é tipicamente representada como vulnerável, passiva, e dependente - figura trá-

gica e santa, a ser salva por um "homem capaz" (BARNES \& MERCER, 2001). Ao analisar a telenovela Viver a Vida percebe-se que essa imagem continua sendo predominante nos meios.

\section{A SEXUALIDADE DA MULHER COM DEFICIÊNCIA}

A mulher com deficiência há muito tempo é infantilizada pela sociedade e considerada assexuada. Uma mulher sem desejos sexuais e sem direito a serviços de saúde sexual e reprodutiva. A sexualidade da mulher com deficiência é considerada por muitos, nula. A mulher com deficiência, e a pessoa com deficiência em geral, é considerada assexuada, principalmente porque a ideia que se tem de sexo, contemporaneamente, está intimamente ligada à função reprodutiva e genital, aos aspectos físicos da sexualidade, excluindo a ideia de que a sexualidade, a sensualidade e o erotismo têm sua origem no campo psicológico das pessoas. Quando essas mulheres buscam informações sobre sexo, são, muitas vezes desestimuladas pelos médicos e familiares a terem uma vida sexual. A vida sexual e a maternidade para as mulheres com deficiência são, muitas vezes, consideradas inapropriadas e perversas.

Esse discurso sobre a sexualidade da mulher com deficiência circula também no discurso médico, que visa à correção da deficiência. Assim, à mulher com deficiência não é dado o devido atendimento de saúde ginecológica, nem é incentivada a maternidade. A falta de incentivo à maternidade também se explica pelo medo da reprodução das deficiências nos filhos, principalmente no caso das deficiências sensoriais (surdez e cegueira).

Além disso, vivemos em uma sociedade que prega a busca incessante pela beleza física e por um padrão de beleza quase inatingível, excluindo completamente o corpo deficiente desse padrão. Assim, a pessoa com deficiência, por não ter a possibilidade de ter um corpo considerado desejável, pode ter dificuldades para desenvolver sua autoestima, fato que atrapalha o desenvolvimento de uma vida sexual. 
As representações culturais da mulher com deficiência (principalmente as mulheres com paraplegia ou tetraplegia) propagam a ideia de mulheres assexuadas, doentes e incapazes. Se durante muitos anos a mulher não teve direito de escolha sobre o próprio corpo apenas pelo fato de ser mulher, a mulher com deficiência sofre duas vezes o preconceito: sofre o preconceito de gênero e o da deficiência. Tomar o poder sobre seu próprio corpo e lutar pela queda desse estereótipo é algo muito novo na luta dos direitos das pessoas com deficiência. Inclusão social não inclui apenas acessibilidade arquitetônica, acesso à educação, transporte e saúde. Inclusão social é incluir em todos os setores da sociedade, dando condições e informação para que a pessoa possa decidir sobre seu próprio corpo e sua sexualidade.

Nesse sentido, a telenovela Viver a Vida é um marco na quebra de estereótipos sobre a sexualidade da mulher com deficiência e na construção de novos significados sobre a deficiência. Em entrevista à revista $\mathrm{Na} \mathrm{Luta}^{4}$, Flávia Cintra, tetraplégica na qual Manoel Carlos se inspirou para criar a personagem Luciana, fala da importância da personagem na vida social das pessoas com deficiência: "A Luciana está, por exemplo, ajudando a esclarecer que existe sexualidade, vida sexual, prazer e alegria na vida de quem possui algum tipo de deficiência".

A sexualidade da pessoa com deficiência se mostra como um assunto emergente na discussão da inclusão da pessoa com deficiência. Se há algum tempo nada era dito sobre esse tema, hoje, a imprensa traz à tona a sexualidade da pessoa com deficiência como assunto central em muitas reportagens.

A maioria das pessoas infantiliza a pessoa com deficiência, dessa forma, a vê como uma pessoa assexuada, uma visão completamente equivocada. As pessoas com deficiência possuem o mesmo corpo, com a mesma produção de hormônios e possuem os mesmos desejos que uma pessoa sem deficiência. A questão da sexualidade ganhou destaque durante a telenovela e também nas reportagens jornalísticas. Em todas as entrevistas com pessoas com deficiência que li para contextualizar a novela, o tema é trazido à tona pelos entrevistados. A entrevistada Mara Gabrilli (revista Veja5, 12/05/2010) admite que a primeira pergunta que fez ao médico, antes de sair do hospital depois de ter sido diagnosticada sua tetraplegia, foi se poderia ter uma vida sexual.

4 Edição 13 (2010) - matéria intitulada Viver a Vida na Vida real.

5 Edição 2164 (12/05/2010) - matéria intitulada Não desisto de ser otimista. 


\section{A SEXUALIDADE DA PESSOA COM DEFICIÊNCIA EM VIVER A VIDA}

A fim de que se entenda, minimamente, a história da personagem Luciana na telenovela, antes de apresentar a análise da representação da sexualidade da pessoa com deficiência em Viver a Vida, apresento um breve resumo da história da personagem.

Luciana era na trama a filha mais velha do casal Marcos e Teresa. De família rica, morava no Leblon, bairro nobre da cidade do Rio de Janeiro e sempre foi muito mimada. Sonhava com a carreira de glamour e sucesso como modelo. Sua nova madrasta, Helena, modelo muito famosa no mundo da moda, ao ser convidada para um desfile em Petra, na Jordânia, pediu a seu agente que Luciana também fosse convidada, a fim de estreitar laços com a enteada. Durante a viagem, as duas discutiram e, após essa discussão, Luciana viajou em carro separado de Helena. Nessa pequena viagem, o ônibus onde estavam Luciana e outras modelos sofreu um acidente, deixando Luciana gravemente ferida. Helena, que havia proibido a presença de Luciana no carro designado a ela sentiu-se culpada, e, quando Luciana é trazida ao Brasil, os médicos confirmaram sua tetraplegia 6 .

A partir desse diagnóstico, a personagem Luciana passou por diversas fases de aceitação da deficiência, tendo que enfrentar seus medos, o preconceito próprio e das pessoas que a cercavam, a precariedade das estruturas públicas para as pessoas com deficiência e as dificuldades dos tratamentos. Luciana precisou adaptar-se à sua condição e aprender a viver com essa nova realidade.

A sexualidade da pessoa com deficiência foi amplamente discutida em Viver a Vida. Por ainda se tratar de um tema tabu na sociedade, mas também uma curiosidade do público em geral, o assunto foi tratado em conversas com os médicos, com outras pessoas com deficiência e com os dois namorados que Luciana teve na trama. Após a seleção de 55 capítulos para análise, selecionei dez capítulos que se referiam ao tema sexualidade, ficando distribuídos da seguinte forma:

6 A tetraplegia é uma incapacitação das funções sensoriais e motoras nas extremidades inferiores e superiores do corpo humano. 
Quadro 1 - Sexualidade

\begin{tabular}{|ll|}
\hline Tema: Sexualidade & \\
\hline Capítulo & Data \\
\hline Conversa do casal sobre o relacionamento & $07 / 12 / 09$ \\
\hline Namorado tira dúvidas com o médico & $14 / 12 / 09$ \\
\hline Questões de sexualidade - conversa entre duas cadeirantes & $08 / 03 / 10$ \\
\hline Namorado dá banho em tetraplégica & $05 / 04 / 10$ \\
\hline Insegurança com sexualidade - conversa com a mãe & $06 / 04 / 10$ \\
\hline A decisão de transar & $14 / 04 / 10$ \\
\hline A primeira relação sexual & $15 / 04 / 10$ \\
\hline $\begin{array}{l}\text { Conversa sobre a primeira relação sexual depois do diagnóstico de } \\
\text { tetraplegia }\end{array}$ & $16 / 04 / 10$ \\
\hline Noite de núpcias & $07 / 05 / 10$ \\
\hline Noite de núpcias - Continuação & $08 / 05 / 10$ \\
\hline
\end{tabular}

Fonte: Silveira (2012)

Enquanto namorava Jorge, Luciana tentou começar uma conversa sobre sexualidade com ele (07/12/09). Mas ao ver que ela própria não entendia ainda sobre sua sexualidade como pessoa com deficiência, acabou desistindo da conversa. Por ter muitas dúvidas em relação à sexualidade de Luciana, Jorge conversa com o irmão Miguel, médico de Luciana, a fim de esclarecer alguns pontos (14/12/09). Os dois mantêm um longo diálogo de caráter pedagógico sobre o assunto:

Jorge: Miguel, eu tenho uma pergunta pra te fazer, eu fico até meio sem jeito mas, só você pode me ajudar. É, a Luciana vai poder ter uma vida sexual normal, como antes?

Miguel: É, Jorge, é muito cedo ainda pra gente saber como é que vai ser a questão do prazer sexual da Luciana. Mas o que eu posso te dizer, é que, clinicamente, não tem nada que impeça ela de ter relações sexuais7.

Jorge: Mas ela não tá tetraplégica?

Miguel: Ela está tetraplégica, mas desde quando desejo, amor, tesão, tem a ver só com movimentação? Não! A questão do prazer, principalmente do prazer feminino, passa muito mais aqui ó, pela cabeça. E você vai aprender, aos poucos, é, de estimular mesmo o corpo da Lu, de achar nela, explorar, novas áreas sensíveis.

É confuso né? Mas deixa eu te explicar. A Luciana, ela não mexe as pernas, mas ela já

7 Destaco em negrito as falas que considero de maior importância nos diálogos. 
apresentou uma certa sensibilidade, o que é um ótimo sinal, entendeu?

Jorge: Tá Miguel, mas é isso que eu não... você me... porque olha só, ela é tetraplégica, mas ela tem alguns movimentos. Ela não mexe as pernas mas ela tem alguma sensibilidade... como é que é isso?

Miguel: Calma Jorge, calma. A relação sexual, geralmente exige alguma adaptação. Principalmente porque esbarra em algumas limitações do cadeirante ou do próprio parceiro. Mas é muito cedo ainda Jorge. Vocês vão se entender.

Jorge: É, eu acho que eu tô ainda meio...

Miguel: Mas ó, é você que vai ter que conduzir essa dança viu, cavalheiro. A Lu realmente vai tá passiva na hora da relação. Mas vocês dois, juntos, vão descobrir o que que é bom, o que que é prazeroso pra vocês.

Jorge: É, parece que a mulher que eu tinha, fosse uma nova mulher, sabe, diferente.

Miguel: Mas de certa forma, ela é uma outra mulher, sim. É sim. Agora presta atenção, na coisa mais importante. De tudo isso que a gente tá conversando, a primeira coisa, a Luciana tem que resgatar a autoestima dela. É muito importante. Porque nesse momento, nesse primeiro momento, a pessoa não se sente atraente sabe. Ela se sente... se vê doente mesmo, né. $E$ aí isso tudo é muito complicado, porque essas coisas, essa sensação atrapalha a libido. Porque só quando você se sente desejável é que você pode desejar outra pessoa, né. Então, em outra palavras, é só quando a vaidade da Luciana voltar é que a sexualidade dela vai poder despertar.

Jorge: Coitada da Lu, coitada! Ela tá renascendo né... pra ela tudo é rigorosamente novo. Justo pra ela que sempre foi tão vaidosa, inspirada, segura. Que barra! Que barra! E que missão essa que agora caiu na minha mão.

Miguel foca na questão de que a sexualidade não está no corpo físico em si, mas na mente, na cabeça da pessoa, e por isso se torna tão importante que a pessoa com deficiência aceite e assuma esse corpo, com suas limitações e tenha uma alta autoestima, sinta-se atraente. Em entrevista à Zero Hora ${ }^{8}$ (10/04/2010), Juliana Carvalho ${ }^{9}$ afirma que a falta de autoestima e aceitação da deficiência é o que impede muitas pessoas com deficiência de terem uma vida sexual.

A expressão de Jorge nesse diálogo é de profunda preocupação, e quando ele fala "coitada", ele realmente mostra que sente pena por tudo que aconteceu, admitindo que essa "barra" agora é dele também, que é uma "missão". Jorge demonstra não apenas medo em relação a essas adaptações, mas uma tristeza por não ter mais a mesma mulher que tinha antes do acidente. A falta

8 Matéria intitulada Uma vida sobre rodas.

9 Paraplégica, 31 anos, autora do livro "Na minha cadeira, ou na tua”, no qual conta sua história de vida, dando ênfase à vida sexual da pessoa com deficiência, e a importância do bom humor e da esperança. 
de informação e o desconhecimento sobre como lidar com a deficiência é o que usualmente deixa as pessoas desconfortáveis.

No mesmo capítulo, Luciana conversa com a mãe e diz que eles não têm mais afinidades, que Jorge não está sabendo lidar e acompanhar as mudanças dessa nova Luciana. Namorar, relacionar-se com uma pessoa com deficiência é relacionar-se também com sua deficiência. Luciana termina o namoro com Jorge e, logo depois, começa a namorar Miguel.

A questão da sexualidade volta a ser mais discutida quando Luciana está a poucas semanas de seu casamento com Miguel. Luciana tem muito medo de que não dê certo, de que ela não sinta prazer, de como será ter uma relação sexual agora que está tetraplégica. Para sanar boa parte de suas dúvidas, Luciana conversa com Camila (08/03/10), uma moça que é cadeirante e casada. Luciana pergunta à $\mathrm{Camila}^{10}$ se ela pode ter relações sexuais, como é, se pode ter orgasmos, etc. Camila a tranquiliza dizendo que ela tem uma vida sexual ativa e que sente prazer, sim. Camila ainda diz que conhece muitas outras mulheres e homens com deficiência que garantem ter uma vida sexual plena. Camila explica que vai ser diferente, mas que ela vai conseguir:

Camila: Lu, você vai se redescobrir. Redescobrir seu corpo, entende? Ó, não pode ficar presa na lembrança de como ele era antes. Eu vou te dizer. Com os poucos movimentos que você já tem, já dá pra fazer muita coisa, viu?! E se seu parceiro for um cara bacana, ele vai te ajudar a conduzir essa dança. Ele sabe das suas limitações e não vai te cobrar o impossível, né? Lu, você tem que pensar que você tem o principal, que você tem sensibilidade, imaginação. O prazer, ele tá aqui ó, na nossa cabeça. Sexo tem muito mais a ver com a emoção do que com o desempenho físico, entende?

Luciana: É verdade. Nossa...eu tava aqui com tanta coisa me assombrando assim, que, sei lá, parece que essa cadeira tinha dado um fim em alguns setores da minha vida, né.

Camila: Ai, que absurdo... é que é tudo muito novo pra você. Você vai ver, daqui um tempo, você vai perceber que seu corpo pode te dar muito mais do que você imagina. Aprender a explorar novas áreas de prazer... E como eu te disse, se o seu parceiro for bacana, ele vai te ajudar, e muito, nessas descobertas todas.

Mais uma vez é reforçada a ideia de que o prazer depende do estado psicológico da pessoa, e não dos movimentos do corpo. Ainda, nesse mesmo

10 A personagem Camila é interpretada pela atriz Vanessa Romanelli, que é cadeirante também fora da ficção. 
diálogo, Camila chama a atenção para a falta de acessibilidade nos motéis da cidade, dizendo que não havia encontrado ainda nenhum motel acessível para cadeirantes.

Tomando coragem e perdendo a vergonha de seu corpo, Luciana convida Miguel a ajudá-la no banho (05/04/10). Miguel fica muito feliz com o convite, porque sabe que isso é um sinal de que Luciana está aceitando seu corpo e abrindo caminho para eles ficarem cada vez mais íntimos. A cena do banho de Miguel e Luciana é intercalada com outras cenas da novela, passando em todos os blocos desse capítulo. É uma cena romântica e sensual, na qual os dois trocam palavras de carinho e Miguel a incentiva a gostar de seu corpo, do jeito que ele é.

No dia seguinte a esse fato (06/04/09), Luciana conversa com a mãe, que a encoraja a tentar ter uma relação sexual com Miguel. Luciana explica o quanto é importante para ela o toque, mas que ainda tem muitas dúvidas sobre a sexualidade, que ainda não se sente preparada para ter uma relação sexual com Miguel. Tereza diz a ela que não tem o que temer, que Miguel sabe exatamente o que acontece com ela, que não está sendo iludido, mas Luciana insiste que tem medo porque é "tudo novo" para ela. Tereza diz que muitas coisas novas aconteceram já, como o primeiro beijo, a primeira transa, a primeira vez que ela sentou na cadeira, e que ela viveu tudo isso, que ela se deixe ter a primeira vez agora também. Luciana diz que a paralisia a fez renascer, fez nascer uma nova Luciana. Ela lembra à mãe que uma das coisas que ela acha complicado para uma relação sexual é o cateterismo (o uso de uma sonda descartável para eliminar a urina). Mesmo Miguel sendo médico, Luciana diz que se envergonha com essas questões. Tereza diz que é apenas uma forma diferente, mas Luciana insiste:

Ai mãe, eu sei... você tá me entendendo, não tá? As coisas são muito mais complicadas pra mim! E nem um pouco glamourosas. Você sabe que as pessoas, elas acham, que o duro é ficar numa cadeira de rodas, só que elas não imaginam, tudo que vem antes disso! Essa questão fisiológica, por exemplo, muda completamente! E a maneira de lidar com o corpo? Eu me olho no espelho, eu vejo uma mulher flácida! Uma mulher morta!

Tereza sugere que ela converse com um ginecologista e Luciana diz que até do ginecologista ela tem vergonha. Tereza fala mais com ela sobre ela ser bonita, jovem e desejável e que agora ela precisa ter paciência com ela mesma e seguir em frente. O corpo acaba sendo a representação máxima da condição humana (Skliar, 2003) e, como já comentamos, vivemos em uma época em que 
a mídia exalta o corpo perfeito, a normalização dos corpos. Aceitar esse novo corpo, com todas as suas limitações, é o primeiro passo para que a pessoa com deficiência perca a vergonha de si mesma e adquira confiança.

É no dia 14/04/10 que Luciana decide realmente transar com Miguel. Antes de ele chegar à sua casa, Luciana pede que arrumem o quarto para ela. A cama é retirada do quarto, tendo apenas um grande colchão com almofadas no centro do quarto. Sentada no colchão com Miguel, olhando fotos suas, antigas, Luciana pergunta, envergonhada se ela pode transar como qualquer outra mulher. Ele diz que para saberem, precisam testar. Miguel brinca com Luciana, tirando a camisa, mas Luciana fica envergonhada e diz que "se é pra rolar, vai rolar”. No capítulo do dia seguinte (15/04/10), seguindo a mesma cena, acontece a primeira relação sexual de Luciana após o acidente. Miguel faz algumas investidas antes que Luciana se sinta à vontade. Luciana diz que para ela é como se fosse a primeira vez, que não é simples e que ela precisa de um tempo para isso. Após alguns beijos e trocas de palavras apaixonadas, Luciana pede que ele tenha paciência com ela. Miguel tira lentamente a roupa de Luciana e diz "a gente tá descobrindo uma nova forma de amar, talvez até mais intenso, mais forte. Deixa eu aprender com você, esse amor novo."

Aparecem cenas dos dois, tapados com lençóis, em diferentes posições na cama. Depois, os dois abraçados na cama, felizes, e Luciana constata: "não pensei que fosse ser assim, tão diferente e tão igual...". Miguel reforça que deixando a insegurança pra trás ele sabia que daria certo. Luciana diz ter sido maravilhoso, e enfatiza o quanto Miguel foi generoso e a tranquilizou para que não ficasse constrangida. Luciana diz que ainda se sente um pouco insegura, mas feliz.

No capítulo do dia 16/04/10, Luciana conversa com a mãe sobre sua primeira vez com Miguel e conta como tudo ocorreu bem. No diálogo, Luciana reforça a ideia de que o sexo está na cabeça, nos sentimentos e não no corpo: "foi diferente mãe, mas sabe que existe tanto desejo entre a gente, que o sentimento acaba envolvendo tudo".

Durante a lua de mel do casal (08/05/10), Luciana diz que ainda tem vergonha de Miguel para algumas coisas, como pedir ajuda para fazer o cateterismo. Luciana diz que sente-se envergonhada de ter de pedir ajuda a ele para tudo. E Miguel diz que isso faz parte do dia a dia deles, assumindo para si o compromisso de ajudar Luciana em todos os momentos.

Ainda, na trama, Luciana fica grávida de gêmeos. A cena do parto dos fiIhos aparece no último capítulo da novela, dando o desfecho de "final feliz", 
típico nos melodramas.

Nos diálogos entre Luciana e Miguel fica evidenciado que uma pessoa com deficiência precisa ter confiança em si e no parceiro para ter relações sexuais. É essa confiança que permite que os dois aprendam como o corpo dos dois funcionam juntos. A ideia de que o sexo está na "mente", na imaginação, nos sentimentos e não no corpo, é uma ideia ressaltada em todos os diálogos sobre sexualidade na novela. Esse tipo de pensamento é o mesmo encontrado nas entrevistas com as pessoas com deficiência nas matérias jornalísticas que fizeram parte do corpus de análise da pesquisa.

Como citado, segundo Barnes e Mercer (2001), na mídia brasileira estão presente as duas figuras clássicas quando se fala em pessoa com deficiência e sexualidade: o homem impotente e incapaz sexualmente e a mulher dependente e passiva, a ser salva por um "homem capaz". As duas são figuras trágicas. Viver a Vida mostrou que a pessoa com deficiência pode ter uma vida sexual plena. E, com a abertura dada pela telenovela, inúmeros depoimentos sobre a vida sexual da pessoa com deficiência foram apresentados na mídia nacional, como o de Fernando Fernandes, modelo e cadeirante que disse à Folha de São Paulo" (14/03/2010): "Hoje tenho plena consciência de que sexo não é só penetração. Fui descobrindo outros meios de ter prazer".

O tema foi tratado de forma esclarecedora e pedagógica pela telenovela, mostrando que a pessoa com deficiência não é assexuada e que a mulher com deficiência pode ter uma vida sexual plena e, ainda, assumir a maternidade.

\section{REFERÊNCIAS}

ALBRECHT, Gary L.; SEELMAN, Katherine D.; BURY, Michael. Introduction. The Formation of Disability Studies. In: ALBRECHT, Gary L.; SEELMAN, Katherine D.; BURY, Michael. Handbook of disability studies. Oaks: Sage Publications, 2001.

BARNES, Colin. Disabling imagery and the media: an exploration of the principles for media representations of disabled people. Halifax: Ryburn Book Production, 1992. Disponível em: <http://www.leeds.ac.uk/disabilitystudies/archiveuk/Barnes/disabling\%2oima gery.pdf>

; MERCER, Geoff. Disability Culture. Assimilation or Inclusion. In: ALBRECHT, Gary L.; SEELMAN, Katherine D.; BURY, Michael. Handbook of disability studies. Oaks: Sage Publications, 2001.

11 Matéria intitulada Meu novo corpo. 
DAVIS, Lennard. Constructing normalcy: the Bell Curve, the novel, and the inventation of the disabled body in the nineteenth century. In: The Disability Studies reader. Nova York: Routledge, 2006.

DE CARLI, Ruvana. Deficiente versus Pessoa Portadora de Deficiência: uma análise discursiva dos jornais Zero Hora e Correio do Povo. Em Questão, vol. 9, n. 2. Porto Alegre. Disponível em: <http://revistas.univerciencia.org/index.php/revistaemquestao/article/view/36 40/3430> Acesso em: 18 agosto 2010.

HALL, Stuart. The work of representation. In: HALL, Stuart (Org). Representation: Cultural representations and signifying practices. London: Sage,1997.

HAMBURGER, Esther. O Brasil Antenado. A sociedade da novela. Jorge Zahar: Rio de Janeiro, 2005.

IBGE. Disponível em: <http://www.ibge.gov.br/home/>. Acesso em: 01 maio 2010.

KELLNER, Douglas. A Cultura da mídia. Estudos Culturais: identidade e política entre o moderno e o pós-moderno. Bauru: Edusc, 2001.

LOPES, Maria Immacolata Vassallo de. Telenovela brasileira: uma narrativa sobre a nação.

Comun. educ., São Paulo, n.26, 1999.

SILVEIRA, Bruna Rocha. Entre a vitimização e a divinização: a pessoa com deficiência em Viver a Vida. Dissertação de mestrado (Mestrado em Comunicação Social). Pontifícia Universidade Católica do Rio Grande do Sul (2012).

SKLIAR, Carlos. Pedagogia (improvável) da diferença; e se o outro não estivesse aí?? Rio de Janeiro: DP\&A Editora, 2003.

RECEBIDO EM: $16 / 10 / 12$

ACEITO PARA PUBLICAÇÃO: 04/11/12 


\section{Bruna Rocha Silveira}

Doutoranda em Educação na UFRGS, pertencente à linha de pesquisa Estudos Culturais em Educação. Mestre em Comunicação Social pela PUCRS. Realiza pesquisa na área de Estudos Culturais, com ênfase em estudos sobre a representação da pessoa com deficiência na mídia. 